\title{
Top-down or bottom-up: Contrasting perspectives on psychiatric diagnoses
}

\author{
Willem MA Verhoeven ${ }^{1,2}$ \\ Siegfried Tuinier ${ }^{\prime}$ \\ Ineke van der Burgt ${ }^{3}$ \\ 'Vincent van Gogh Institute for \\ Psychiatry, Venray, The Netherlands; \\ ${ }^{2}$ Department of Psychiatry, Erasmus \\ University Medical Centre, Rotterdam, \\ The Netherlands; ${ }^{3}$ Department of \\ Human Genetics, Radboud University \\ Medical Centre, Nijmegen, The \\ Netherlands
}

\begin{abstract}
Clinical psychiatry is confronted with the expanding knowledge of medical genetics. Most of the research into the genetic underpinnings of major mental disorders as described in the categorical taxonomies, however, did reveal linkage with a variety of chromosomes. This heterogeneity of results is most probably due to the assumption that the nosological categories as used in these studies are disease entities with clear boundaries. If the reverse way of looking, the so-called bottom-up approach, is applied, it becomes clear that genetic abnormalities are in most cases not associated with a single psychiatric disorder but with a certain probability to develop a variety of aspecific psychiatric symptoms. The adequacy of the categorical taxonomy, the so-called top-down approach, seems to be inversely related to the amount of empirical etiological data. This is illustrated by four rather prevalent genetic syndromes, fragile X syndrome, Prader-Willi syndrome, 22q11 deletion syndrome, and Noonan syndrome, as well as by some cases with rare chromosomal abnormalities. From these examples, it becomes clear that psychotic symptoms as well as mood, anxiety, and autistic features can be found in a great variety of different genetic syndromes. A psychiatric phenotype exists, but comprises, apart from the chance to present several psychiatric symptoms, all elements from developmental, neurocognitive, and physical characteristics.
\end{abstract}

Keywords: genetic disorders, psychiatric symptoms, phenotype, mental disorders

\section{Introduction}

For psychiatry, both on the clinical and the scientific level, genetic disorders form a tremendous challenge since they present a unique opportunity to study psychiatric symptoms in relation to a known etiology and sometimes pathophysiology. Furthermore, genetic abnormalities serve as impetus in the search for candidate genes for psychiatric syndromes (Muir et al 2006; Blackwood et al 2007). A comparable opportunity is presented by neurological disorders that are accompanied by psychiatric symptoms, like Parkinson's disease, multiple sclerosis, and epilepsy (Verhoeven et al 2006; Lyketsos et al 2007).

The categorical psychiatric taxonomies like the Diagnostic and Statistical Manual (DSM) of the American Psychiatric Association are in these cases routinely used for 'diagnosing' psychiatric diseases, and often result in several diagnoses at the same time. This phenomenon is called comorbidity. As stated by van Praag (2000), the nosological way of thought carries with it harmful side effects such as proliferation of new diagnoses and magnification of comorbidity. In addition, current psychiatric diagnostics are based on the presumption that a common pathophysiology underlies psychiatric syndromes that were primarily tailored by consensus and not by empirical evidence. Thus, as in behavioral neurology, psychiatry should also operate from the bottom-up, 'beginning with the emergence of pathology in the brain and attempting to understand the emerging of clinical syndromes out of this pathology' (Lyketsos et al 2007). This 'bottom-up' approach also needs a theoretical framework because, 
without theory, categories tend to increase as is illustrated by the growing number of the subsequent DSM-versions (Egger et al 2007). Clinical syndromes, out of such a 'bottom-up' orientation are not congruent with DSM categories but are reflections of a certain probability to develop a variety of psychiatric and neurocognitive symptoms (Verhoeven et al 2007, 2008).

The futility of the top-down approach is best illustrated by the 'disorder' called mental retardation that is not a disease or a disability but a 'syndrome grouping that includes a heterogenous group of clinical conditions, ranging from genetic to nutritional, infectious, metabolic or neurotoxic conditions' (Salvador-Carulla and Bertelli 2007). In case of genetic disorders, the chance to define a phenotype is proportional to the prevalence of the disorder and the research efforts on its phenomenology and pathophysiology. The same holds for emerging treatment modalities that will be increasingly targeted not at DSM diagnoses but at functional impairments crossing nosological boundaries (Verhoeven and Tuinier 2001; Green 2007).

The proposed bottom-up approach will be exemplified by a series of patients with psychiatric symptoms and genetic disorders ranging from rather prevalent to rare. It will be advocated that the adequacy of the categorical taxonomy is inversely proportional to the amount of scientific information.

\section{Examples of the bottom-up orientation \\ Fragile $X$ syndromes}

Fragile X syndrome (FXS) is the most common inherited cause of mental retardation with an overall prevalence of 1 in 2000 to 1 in 3000 and originates from a trinucleotide repeat expansion of three bases (cytosine-guanine-guanine) in the fragile X mental retardation-1 gene (FRM1; Xq27.3) leading to hypermethylation and consequent silencing of the FMR1 gene (Penagarikano et al 2007). A small expansion or premutation has approximately 55-200 repeats and occurs in 1 in 700 females. The full mutation that has at least 200 repeats is associated with the syndrome. The premutation (70-200 repeats) in males is associated with the fragile $\mathrm{X}$-associated tremor/ataxia syndrome (FXTAS) and in females with a premature ovarian failure (POF). Recently, however, Adams and colleagues (2007) described that female carriers may also develop FXTAS. FXS, FXTAS, and POF are caused by a failure in the transcription of FRM1mRNA, either absent (FXS) or in excess (FXTAS and POF). The latter leads to a RNA toxic gain of function (Tassone et al 2007). The protein product FRMp which is absent in FXS and normal or low in the premutation is involved in synaptic function and structure (Jacquemont et al 2007). Overexpression of FRM1mRNA results in premature ovarian failure (Welt et al 2004; Lin and Yang 2006) and forms inclusions in neurons and glia cells in carriers that leads subsequently to cell damage and to a dementia syndrome characterized by ataxia and other neurological manifestations (Jacquemont et al 2004; BerryKravis et al 2007).

Some structural abnormalities of the brain have been demonstrated in FXS, especially an increased size of hippocampus, caudate, thalamus, and lateral ventricle whereas the cerebellar vermis is smaller (Moore et al 2004; Koukoui and Chaudhuri 2007). FXTAS shows prominent white matter disease in the periventricular, subcortical, and mid-cerebellar peduncle as well as global brain atrophy (Adams et al 2007).

On the behavioral level, FXS is well known to be associated with irritability, hypotonia, mild motor delays, temper tantrums, and language delays during the first years. In addition, autistic features, shyness, and social anxiety are frequently reported. The level of intellectual capacity varies between 40 and 88 , dependent on whether or not there is a complete or incomplete inactivation of the FRM1 gene. Affected females with a full mutation have a borderline to mild mental retardation. In a substantial number of patients with the full mutation, hyperactivity tends to improve during adulthood. The most prominent psychiatric symptom in both males and females is anxiety, particularly social anxiety that is especially present in individuals without hyperactivity and irritability. In addition, obsessive compulsive symptoms are frequently observed that co-occur with perseverations or repetitive behaviors. Thus, the psychiatric phenotype of FXS comprises developmental delay, anxieties, autistic and obsessive compulsive features (Hagerman 2005). Female carriers of FXS are at risk for the development of affective symptoms and social anxiety (Franke et al 1998; Hageman et al 2007). The 'social anxiety' may look like, but is not adequately covered by the DSM-diagnosis of social phobia or social anxiety. The same holds for other symptomatology.

The neuropsychiatric profile of FXTAS is dominated by deficits in cognitive functioning associated with or preceded by symptoms of depression and anxiety as well as irritability and behavioural disinhibition, a symptom profile that is usually seen in dementias. The full psychiatric profile, however, has not been investigated as yet (Bacalman et al 2006).

\section{Noonan syndrome}

Noonan syndrome (NS) is an autosomal dominant genetically heterogeneous disorder with an estimated incidence of 
1:1500 live births. The diagnosis of NS is primarily clinical and can be made by using a scoring system, listing major and minor congenital and morphological anomalies (Van der Burgt et al 1994). NS should be considered when typical facial dysmorphias are present as well as short stature, a variety of heart defects, particularly pulmonic stenosis and hypertrophic cardiomyopathy and skeletal deformations like pectus excavatum and carinatum. Additional features are cryptorchidism, lymphatic dysplasias, abnormal bleeding, and a lower level of IQ (Tartaglia and Gelb 2005).

Linkage analysis has demonstrated that the gene for NS is located on the distal part of chromosome 12q (Jamieson et al 1994). Subsequently, it was found that missense mutations in the PTPN11 gene (12,q24.1) account for about half of NS patients (Tartaglia et al 2001). In addition, germline mutations in the KRAS gene were reported in a minority of patients with severe forms of NS (Schubbert et al 2006). Recently, a novel mutation in another gene involved in the RAS-MAPK pathway was discovered in a subset of patients with NS, the SOS1 gene (Roberts et al 2006). Mutations in the PTPN11 gene result in expression of a SHP-2 protein with an increased phosphatase activity that may lead to aberrant neural cell-fate decisions during development which may be implicated in cognitive impairments in NS (Gauthier et al 2007).

Data about the psychological and psychiatric characteristics of NS patients are scarce. In about one-third of patients a mild mental retardation is found. In most patients, however, the level of intelligence falls within the normal range (Allanson 2005). Mood disturbances as well as social, communication, and planning problems have been found in children with NS (Wood et al 1995; Van der Burgt et al 1999; Sarimski 2000; Lee et al 2005).

Given the prevalence of NS, it is remarkable that virtually no reports have been published about classical psychiatric syndromes and that hardly any information is available about the cognitive and mental health status of adult patients with NS. Recently, Verhoeven and colleagues (2008) reported on a group of 10 adult NS patients not referred for psychiatric or behavioral problems. Apart from a variable level of intelligence, there was a moderately impaired social cognition in terms of emotion recognition and alexithymia. In some patients mild signs of anxiety and lowered mood were observed that, however, did not meet the criteria for a specific psychiatric disorder.

Interestingly, the neuropsychiatric profile of NS comprises subtle deficits in social and emotional recognition while, given the developmental problems associated with the somatic comorbidity, much more psychiatric morbidity would be expected. It can be hypothesized that NS 'protects' against the development of major psychiatric illnesses.

\section{$22 q$ I I deletion syndrome}

This syndrome (22q11DS), previously termed velo-cardiofacial syndrome, is a common genetic disorder estimated to affect 1 in 4000 individuals and is associated with a deletion of varying size on the long arm of chromosome 22 (22q11.2). Several genes that are involved in the deletion have been investigated of which that coding for catecholo-methyl transferase (COMT) and the TBX1 gene are the best known. Some evidence is available that polymorphism for the COMT gene is associated with differences in brain anatomy (Van Amelsfoort et al 2008). Magnetic resonance imaging has demonstrated wide spread deficits in white matter and reduced brain volumes (Van Amelsfoort et al 2004; Schaer et al 2006). Polymicrogyria, however, is reported most frequently (Robin et al 2006).

In addition, COMT has been demonstrated to be associated with cognitive deficits, irrespective of diagnosis (Akil et al 2003; Diamond 2007). Since the gene for COMT, an enzyme involved in the degradation of dopamine, is located in the commonly deleted region in patients with $22 \mathrm{q} 11$ deletion syndrome, Karayiorgou and colleagues (1998) initially suggested an association between schizophrenia and a low activity allele of COMT. This observation could, however, not be replicated in 22q11DS patients with psychotic disorders (Murphy et al 1999) nor in patients with schizophrenia (Arinami et al 2001; De Chaldée et al 2001; Glaser et al 2006; Williams et al 2007).

With respect to the TBX1 gene, several lines of evidence support the hypothesis that it is involved in the vascular perfusion of the embryonic brain (Robin et al 2006). It has been demonstrated that haploinsufficiency of TBX1 results in a spectrum of distinct vascular and heart defects (Vitelli et al 2002). TBX1 variations in psychiatric populations most probably do not contribute to major psychiatric disorders (Funke et al 2007).

The clinical phenotype of 22q11DS is characterized by a variable degree of intellectual disability, cardiac anomalies, pharyngeal hypotonia and cleft palate, abnormal facies, thymic hypoplasia, and hypocalcaemia due to hypoparathyroidism (Shprintzen 2000). The behavioral phenotype in childhood and adolescence comprises social withdrawal, a special attachment to mother or other caregivers, poor social skills, emotional instability, affective problems, anxieties, diminished flexibility, and attention deficits (Swillen et al 
1999; Antshel et al 2007; Majerus et al 2007). In adults with 22q11DS, a discrepancy between verbal and performal IQ as well as an impaired visuoperceptual ability and a diminished comprehension of abstract and symbolic language has been found (Henry et al 2002; Verhoeven et al 2007). In terms of personality constructs most patients score high on neuroticism and low on agreeableness, a profile associated with adjectives like shy, moody, irrational, and unempathetic (Verhoeven et al 2007).

In patients after adolescence a high prevalence of several psychiatric illnesses is reported including bipolar (spectrum) disorder, anxiety disorder, obsessive compulsive disorder, autism spectrum disorders and psychotic disorders, especially schizophrenia (Shprintzen et al 1992; Papoulos et al 1996; Murphy et al 1999; Vogels et al 2002; Jolin et al 2006; Vorstman et al 2006). It should be stressed, however, that the psychotic symptoms are totally different from that described in the DSM-schizophrenia category (Sphrintzen 2000; Verhoeven et al 2007). 'Going up' from the microdeletion to the psychiatric symptom profile does not lead to a diagnosis of schizophrenia unless a narrow-minded clinical observation is used. Following the reverse trajectory, going from schizophrenia to a 22q11DS, no association has been demonstrated. Several large-scale studies in patients with schizophrenia have shown a prevalence of 22q11 deletion syndrome of less than 1\% (Sugama et al 1999; Arinami et al 2001; Ivanov et al 2003; Horowitz et al 2005; Hoogendoorn et al 2008). Genome-wide genetic linkage in patients with schizophrenia did not confirm a linkage with 22q11 (Shaw et al 1998; Faraone et al 1998; Kaufmann et al 1998; Gurling et al 2001; Hamshere et al 2005; Fanous et al 2007).

\section{Prader-Willi syndrome}

Prader-Willi Syndrome (PWS) is a multisystem disorder with an estimated prevalence of 1:10.000-15.0000 and is accompanied by a variable degree of intellectual impairment. The syndrome arises from the lack of expression of genes on the paternally derived chromosome $15 \mathrm{q} 11-13$ as a result of a paternal deletion (75\%), an uniparental maternal disomy (UPD; 20\%), or other chromosomal anomalies. All lead to the loss of expression of a group of genes on 15q1113 that are only expressed from the paternally inherited chromosome because the maternal contribution is silenced. The function of several imprinted genes in this region is unknown (Cassidy and McCandless 2005). One of the imprinted genes is NECDIN that is thought to be related to respiratory disturbances in PWS (Zanella et al 2008). Since the $\gamma$-aminobutyric acid (GABA) receptor subunit genes in this region are all nonimprinted, their expression is increased in cases with UPD and decreased in those with a deletion (Bittel et al 2003). Support for an involvement of GABA-receptor genes in the phenotype was presented by Ebert and colleagues (1997) who found elevated plasma levels of GABA in PWS patients irrespective of the genetic etiology. This observation was interpreted as a compensatory mechanism in response to hyposensitivity of a subset of GABA receptors. Later, a PET-scan study demonstrated a reduced number of $\mathrm{GABA}_{\mathrm{A}}$ receptors in one specific brain area of PWS patients (Lucignani et al 2004).

With respect to the genes involved in the expression of the PWS genotype, it has recently be shown that, apart from the nonexpression of paternally expressed genes from the 15q11-13 region, PWS differs enormously from controls in the expression of genes located on other chromosomes of which several are implicated in neurodevelopment and function (Bittel et al 2007).

Since many of the features of PWS are suggestive for a hypothalamic/pituitary dysfunction, both postmortem and neuroimaging studies have been performed. Swaab and colleagues (1995) found a significantly lower number of small oxytocin secreting neurons in the paraventricular hypothalamus and, in some cases, a reduction of vasopressin secreting neurons as well as a diminished vasopressin precursor processing. MRI-studies have shown a reduction in the pituitary height suggestive for alterations on the hypothalamic-pituitary level (Iughetti et al 2008) as well as structural brain anomalies such as enlarged ventricles (Miller et al 2006).

The clinical manifestations of PWS are: reduced fetal activity during pregnancy, a transient severe hypotonia and feeding problems in the neonatal period, a variable degree of intellectual disability, delayed developmental milestones, hyperphagia, obsessive-compulsive features like skin picking, controlling behaviors and repetitive question asking, temper tantrums, stubbornness, and a variety of hypothalamic dysfunctions. The latter become manifest as hypogonadism, short stature, sleep disturbances and defects in temperature regulation (Cassidy and Candless 2005).

Patients with UPD have been demonstrated to differ from those with a deletion with respect to physical, cognitive, and behavioral parameters. Moreover, a larger deletion is associated with more obsessive compulsive behaviors, poorer adaptive behavior and cognitive dysfunction (Bittel et al 2006).

With respect to the psychopathology in patients with PWS, a broad array of disorders with a prevalence up to one third of the patients is described that ranges from (atypical) 
psychotic and bipolar affective disorder (Verhoeven et al 1998, 2003a; Verhoeven and Tuinier 2006; Soni et al 2007) to obsessive compulsive disorder (Clarke et al 2002), attentiondeficit/hyperactivity disorder (Wigren and Hansen 2005) and pervasive developmental disorder (Descheemaecker et al 2006). Concerning psychotic disorders, an association has been demonstrated with UPD (Boer et al 2002; Vogels et al 2003; Verhoeven et al 2003a, 2003b). Since the gene for the $\alpha_{5}$ subunit receptor is located in the 15q11-13 region, it was hypothesized that GABA-ergic neurotransmission may be involved in the pathophysiology of bipolar illness in general because of the high prevalence of this disorder in PWS (Ewald et al 1994).

As in the 22q11 deletion syndrome, the 'bottom-up' approach, form the genetic defect to the psychiatric symptom profile, does not lead to a simple categorical psychiatric classification but to the description of a syndrome that encompasses developmental contingencies from the prenatal period, hypothalamic dysfunctions and a certain probability of behavioral disturbances and psychiatric symptoms, the so called Prader-Willi neuropsychiatric phenotype.

\section{Rare genetic disorders}

In contrast to the above mentioned genetic syndromes with their well described behavioral phenotypes, the psychiatrist may encounter other genetic disorders. The search for such disorders is indicated if cognitive functions are compromised and a developmental delay or dysmorphias are present. Four patients will be described who were referred for neuropsychiatric evaluation because of psychotic or depressive symptoms.

\section{Case I}

Case 1 is a 57 -year-old male who had been treated from his twenties with several antidepressants and mood stabilizers for mood disturbances. His somatic history showed diabetes mellitus type 2 with neuropathy, mild hypertension, and loss of libido and erectile dysfunction. The family history was void of mental disorders, congenital anomalies, and neuropsychiatric disorders. Neuropsychiatric evaluation revealed lowered mood, fatigue, hypersomnia, and apathy. His total IQ was 128. There were no relevant somatic abnormalities apart from central obesity (weight: $115 \mathrm{~kg}$; BMI 35) and infertility due to azoospermia. Laboratory investigation showed a low level of testosterone $(4.6 \mathrm{nmol} / 1$; normal range 9-18 nmol/l) and increased levels of luteinizing hormone and follicle-stimulating hormone. Because of the combination of infertility and testosterone deficiency, cytogenetic analysis was performed that revealed a Robertsonian translocation 13;
14 (karyotype: 45,XY der(13; 14)(q10; q10). This autosomal aberration is the most frequent chromosomal abnormality demonstrated in male infertility (Tuerlings et al 1998). A diagnosis of atypical depression due to testosterone deficiency was made and all psychotropics were tapered off. Subsequently the patient became less apathetic and his mood level normalized. He was referred to the endocrinologist for treatment with testosterone.

Although lower testosterone levels are frequently seen in patients with type 2 diabetes (Kapoor et al 2007), it is possible that in this patient the etiology of both infertility and low testosterone as well as his long lasting atypical mood disorder is of chromosomal origin, although no health problems are described in this translocation.

\section{Case 2}

Case 2 is a 24-year-old female with moderate mental retardation whose history is characterized by a developmental delay. Her family history did not reveal any abnormalities. At the age of 14 she developed recurrent episodes with anxiety, irritability, mood instability, perceptual disturbances, and challenging behaviors. A diagnosis of psychotic disorder with comorbid atypical autism was made and the patient was treated with antipsychotics. At neuropsychiatric examination, no dysmorphias were observed. She complained about severe anxieties and extreme responses to environmental stimuli and chaotic behaviour. Her total IQ was 48. All laboratory parameters were normal. Cytogenetic analysis revealed a partial duplication of chromosome 13 [(13)(q14.1q21.3)]. Treatment with antipsychotics was discontinued and an adaption of the environmental contingencies resulted in a clear amelioration of her general functioning.

In this patient a previously undescribed chromosomal abnormality was found that was considered to explain the moderate mental retardation as well as the vulnerability to develop anxiety symptoms.

\section{Case 3}

Case 3 was hospitalized for the first time at the age of 81 because of disorientation, self neglect, and paranoid ideation. Her history showed long-lasting social incompetence, paranoid attitude, and social isolation. No formal psychiatric diagnosis was ever made. Neuropsychiatric evaluation disclosed symptoms of a major depression with psychotic features and autistic behavior. Her IQ was 82 . Genetic analysis showed a balanced translocation between the short arm of chromosome $\mathrm{X}$ and the long arm of chromosome $19[46, \mathrm{X}, \mathrm{t}(\mathrm{X} ; 19)(\mathrm{p} 11.4$; q13.3)] (Verhoeven et al 2007). 
In this older patient the genetic disorder may be responsible for the low level of intellectual function and the disordered communication.

\section{Case 4}

Case 4 is a 31-year-old female who was referred for recurrent short-lasting psychotic episodes for which she had been treated with antipsychotics for several years. Her history demonstrated developmental delay, poor social skills, and learning difficulties. At the age of 10, an autistiform disorder was considered. There was no family history of mental retardation or mental illness. Neuropsychiatric evaluation revealed minor dysmorphias and a lack of social reciprocity, verbal perseverations, paranoid attitude, anxiety, mood instability and irritability. Her total IQ was 68. Chromosome analysis demonstrated a translocation between chromosomes 2 and $10(46, \mathrm{XX}, \mathrm{t}(2 ; 10)(\mathrm{p} 23 ; 22.1)$. Treatment with risperidone and valproic acid resulted in a stabilization of mood and disappearance of psychotic symptoms over several years (Verhoeven et al 2006). The social incompetence remained.

As in the other patients, an undescribed translocation was found that may probably explain the mild mental retardation and the psychiatric symptoms.

\section{Discussion}

From the presented examples it becomes clear that in case of rather prevalent genetic syndromes, a phenotype can be outlined. This means that the chance to present somatic or behavioral sign and symptoms is increased compared with the normal population. There is no linear relationship between genes and phenotype because phenotypic variability is the rule (Sheldon and Turk 2000; Gropman and Adams 2007). The concept of a behavioral phenotype should comprise not only behavioral elements and psychiatric symptoms but also physical features (Turk and Hill 1995) since all are expressions of the genotype modified by environmental and epigenetic factors. Furthermore, it should be noticed that neurocognitive development can be influenced by an initial deficit resulting in a phenotypic amalgam of the deficit and its developmental consequences (Cornish et al 2004). This phenomenon is analogue to that of trait amplification as described for borderline personality disorders by Paris (1994).

When the phenotype is restricted to psychiatric disorders, any specificity for a genetic disorder is absent since psychotic symptoms as well as mood and anxiety disorders are described in a great variety of different genetic syndromes (Bassett et al 2000; Verhoeven et al 2004). Examples are
PWS and 22q11DS in which a great variety of psychiatric syndromes can be found that do not give any clue to the existence of a specific genetic etiology. If one adds, however, neonatal hypotonia, skin picking and hyperphagia or nasal speech, conotruncal heart malformations and cleft palate, then the identification of the syndrome is rather easy.

In almost all syndromes described above, autism or autistic-like features may be present. Such features must always lead to a neurogenetic investigation because of the high prevalence of identifiable medical conditions (Bradley Schaefer and Lutz 2006). The concept of autism as advanced by Gillberg (1992) may be of heuristic value since it acknowledges that autism is a behavioral syndrome shading into several other disorders. This behavioral syndrome can be caused by a variety of medical conditions and each of these conditions represents a separate disease entity (Gillberg 1992; Gillberg and Billstedt 2000).

Following the bottom-up approach, the analysis of the complex interplay between biological and contextual systems may eventually lead to a true functional classification of mental disorders. The search for candidate genes for psychiatric disorders has given great impetus for this endeavor. A good example is the discovery of the DICS1 gene in one family that was originally thought to be causally related to schizophrenia (St. Clair et al 1990). Later a biochemical cascade became clear with consequences for neurodevelopment and function that predispose for psychiatric symptoms across diagnoses (Blackwood et al 2007; Millar et al 2007).

The phrentic adherence of psychiatry to etiologically neutral prototypical behavioral syndromes, categorical diagnoses, severely hampers the cross talk with biological research. It should be realized that a gene defect does not code for a categorical psychiatric disorder but for a biological dysfunction that has a certain probability to be associated with a range of psychiatric symptoms. As stated by Kendler (2005) 'the appropriate level of explanation for gene action is much more likely to be basic biological or mental processes that contribute to psychiatric disorders rather than the disorders themselves'.

\section{Disclosure}

The authors report no conflicts of interest in this work.

\section{References}

Adams JS, Adams PE, Nguyen D, et al. 2007. Volumetric brain changes in females with fragile X-associated tremor/ataxia syndrome (FXTAS). Neurology, 69:851-59.

Akil M, Kolachana BS, Rothmond DA, et al. 2003. Catechol-omethyltransferase genotype and dopamine regulation in human brain. J Neurosci, 23:2008-13. 
Allanson JE. 2005. Noonan syndrome. In: Cassidy SB, Allanson JE (eds). Management of Genetic Syndromes, 2nd ed. New York: Wiley-Liss, pp. 385-97.

Antshel KM, Stallone K, AbdulSabur N, et al. 2007. Temperament in velocardiofacial syndrome. J Intell Disabil Res, 51:218-27.

Arinami T, Ohtsuki T, Takase K, et al. 2001. Screening for 22q11 deletions in a schizophrenia population. Schizophr Res, 52:167-70.

Bacalman S, Farzin F, Bourgeois JA, et al. 2006. Psychiatric phenotype of the fragile X-associated tremor/ataxia syndrome (FXTAS) in males: newly described fronto-subcortical dementia. J Clin Psychiatry, 76:87-94.

Bassett AS, Chow EWC, Weksberg R. 2000. Chromosomal abnormalities and schizophrenia. Am J Med Genet, 97:45-51.

Berry-Kravis E, Abrams L, Coffey SM, et al. 2007. Fragile X-associated tremor/ataxia syndrome: clinical features, genetics, and testing guidelines. Mov Disord, 22:2018-30.

Bittel DC, Kibiryeva N, Talebizadeh Z, et al. 2003. Microarray analysis of gene/ transcript expression in Prader-Willi syndrome: deletion versus UPD. J Med Genet, 40:568-74.

Bittel DC, Kibiryeva N, Butler MG. 2006. Expression of 4 genes between chromosome 15 breakpoints 1 and 2 and behavioural outcomes in Prader-Willi syndrome. Pediatrics, 118:276-83.

Bittel DC, Kibiryeva N, Sell SM, et al. 2007. Whole genome microarray analysis of gene expression in Prader-Willi syndrome. Am J Med Genet, 143A:430-42.

Blackwood DH, Pickard BJ, Thomson PA, et al. 2007. Are some genetic risk factors common to schizophrenia, bipolar disorder and depression? Evidence from DISC1, GRIK4 and NRG1. Neurotox Res, 11:73-83.

Boer H, Holland A, Whittington J, et al. 2002. Psychotic illness in people with Prader-Willi syndrome due to chromosomal 15 maternal uniparental disomy. Lancet, 359:135-6.

Bradley Schaefer G, Lutz R. 2006. Diagnostic yield in the clinical genetic evaluation of autism spectrum disorders. Genet Med, 8:549-56.

Cassidy SB, McCandless SE. 2005. Prader-Willi syndrome. In: Cassidy SB, Allanson JE (eds). Management of Genetic Syndromes, 2nd ed. New York: Wiley-Liss, pp. 429-48.

Clarke DJ, Boer H, Whittington J, et al. 2002. Prader-Willi syndrome, compulsive and ritualistic behaviours: the first population-based survey. Br J Psychiatry, 180:358-62.

Cornish, KM, Turk J, Wilding J, et al. 2004. Annotation: deconstruction the attention deficit in fragile $\mathrm{X}$ syndrome: a developmental neuropsychological approach. J Child Psychol Psychiatry, 45:1042-53.

De Chaldée M, Corbex M, Campion D, et al. 2001. No evidence for linkage between COMT and schizophrenia in a French population. Psychiatry Res, 102:87-90.

Descheemaeker MJ, Govers V, Vermeulen P, et al. 2006. Pervasive developmental disorders in Prader-Willi syndrome. Am J Med Genet, 140A:1136-42.

Diamond A. 2007. Consequences of variations in genes that affect dopamine in prefrontal cortex. Cereb Cortex, 17:161-70.

Ebert MH, Schmidt DE, Thompson T, et al. 1997. Elevated plasma gamma-aminobutyric acid (GABA) levels in individuals with either Prader-Willi syndrome or Angelman syndrome. J Neuropsychiatry Clin Neurosci, 9:75-80.

Egger JIM, De Mey HRA, Janssen G. 2007. Assessment of executive functioning in psychiatric disorders: Functional diagnosis as the ouverture of treatment. Clin Neuropsychiatr, 4:83-90.

Ewald H, Mors O, Flint T, et al. 1994. Linkage analysis between manicdepressive illness and the region on chromosome $15 \mathrm{q}$ involved in Prader-Willi syndrome, including two $\mathrm{GABA}_{\mathrm{A}}$ receptor subtype genes. Hum Hered, 44:87-94.

Fanous AH, Neale MC, Webb BT, et al. 2007. A genome-wide scan for modifier loci in schizophrenia. Am J Med Genet Neuropsychiatr Genet, B144:589-95.

Faraone SV, Matise T, Svarkic D, et al. 1998. Genome scan for EuropeanAmerican schizophrenia pedigrees: results of the NIMH genetics initiative and the millennium consortium. Am J Med Genet, 81:290-95.
Franke P, Leboyer M, Gänsicke M, et al. 1998. Genotype-phenotype relationship in female carriers of the permutation and full mutation of FMR-1. Psychiatry Res, 17:113-27.

Funke BH, Lenez T, Finn ChT, et al. 2007. Analysis of TBX1 variation in patients with psychotic and affective disorders. Mol Med, 13:407-14.

Gauthier AS, Furstoss O, Araki T, et al. 2007. Control of CNS cell-fate decisions by SHP-2 and its dysregulation in Noonan syndrome. Neuron, 54:245-62.

Gillberg C. 1992. The Emanuel Miller Memorial Lecture 1991: autism and autistic-like conditions: subclasses among disorders of empathy. J Child Psychol Psychiatry, 33:813-42.

Gillberg C, Billstedt E. 2000. Autism and asperger syndrome: coexistence with other clinical disorders. Acta psychiatr Scand, 102:321-30.

Glaser B, Moskvina V, Kirov G, et al. 2006. Analysis of ProDH, COMT and ZDHHC8 risk variants does not support individual or interactive effects on schizophrenia susceptibility. Schizophr Res, 87:21-7.

Green MF. 2007. Stimulating the development of drug treatments to improve cognition in schizophrenia. Annu Rev Clin Psychol, 3:159-80.

Gropman A, Adams D. 2007. Atypical patterns of inheritance. Semin Pediatr Neurol, 14:34-45.

Gurling HMD, Kalsi G, Brynfolfson J, et al. 2001. Genomewide genetic linkage analysis confirms the presence of susceptibility loci for schizophrenia on chromosomes 1q32.2, 5q33.2 and 8p21-22 and provides support for linkage to schizophrenia on chromosomes 11q23.3-24 and 20q12.1-11.23. Am J Hum Genet, 68:661-73.

Hageman S, Van den Eede F, Vandendriessche F, et al. 2007. Psychopathology in female carriers of the fragile X mutation. Tijdschr Psychiatr, 49:327-31.

Hagerman RJ. 2005. Fragile X syndrome. In: Cassidy SB, Allanson JE (eds). Management of Genetic Syndromes, 2nd ed. New York: WileyLiss, pp. 251-63.

Hamshere ML, Bennett Ph, Williams N, et al. 2005. Genome wide linkage scan in schizoaffective disorder. Significant evidence for linkage at $1 \mathrm{q} 42$ close to DISC1, and suggestive for evidence at 22q11 and 19p13. Arch Gen Psychiatry, 62:1081-88.

Henry JC, van Amelsvoort T, Morris RG, et al. 2002. An investigation of the neuropsychological profile in adults with velo-cardio-facial syndrome (VCFS). Neuropsychologia, 40:471-78.

Hoogendoorn MLC, Vorstman JAS, Jalali GR, et al. 2008. Prevalence of 22q11.2 deletions in 311 Dutch patients with schizophrenia. Schizophr Res, 98:84-8.

Horowitz A, Shifman S, Rivlin N, et al. 2005. A survey of the 22q11 microdeletion in a large cohort of schizophrenic patients. Schizophr Res, 73:263-67.

Iughetti L, Bosio L, Corrias A, et al. 2008. Pituitary height and neuroradiological alterations in patients with Prader-Labhart-Willi syndrome. Eur J Pediatr, 167:701-2.

Ivanov D, Kirov G, Norton N, et al. 2003. Chromosome 22q11 deletions, velo-cardio-facial syndrome and early-onset psychosis. Br J Psychiatry, 183:409-13.

Jacquemont S, Farzin F, Dall D, et al. 2004. Aging in individuals with the FMR1 mutation. Am J Ment Retard, 109:154-64.

Jacquemont S, Hagerman RJ, Leehey MA. 2007. Fragile-X syndrome and fragile X-associated tremor/ataxia syndrome: two faces of FMR1 Lancet Neurol, 6:45-55.

Jamieson CR, Van der Burgt I, Brady AF, et al. 1994. Mapping a gene for Noonan syndrome to the long arm of chromosome 12. Nat Genet, 8:357-60.

Jolin EM, Weller EB, Weller RA. 2006. A biological model to study the genetics of psychotic, mood, and anxiety disorders: the velocardiofacial syndrome. Curr Psychiatry Rep, 8:90-5.

Kapoor D, Aldred H, Clark S. 2007. Clinical and biochemical assessment of hypogonadism in men with type 2 diabetes. Diabetes Care, 30:911-17.

Karayiorgou M, Gogos JA, Galke BL, et al. 1998. Identification of sequence variants and analysis of the role of the catechol-o-methyl-transferase gene in schizophrenia susceptibility. Biol Psychiatry, 43:425-31. 
Kaufmann CA, Suarez B, Malaspina D, et al. 1998. NIMH genetics initiative millennium schizophrenia consortium: linkage analysis of AfricanAmerican pedigrees. Am J Med Genet, 81:282-89.

Kendler S. 2005. 'A gene for...': The nature of gene action in psychiatric disorders. Am J Psychiatry, 162:1243-52.

Koukoui SD, Chaudhuri A. 2007. Neuroanatomical, molecular genetic, and behavioural correlates of fragile X syndrome. Brain Res Rev, 53:27-38.

LeeD, Portnoy S, Hill P, et al. 2005. Psychological profile of children with Noonan syndrome. Dev Med Child Neurol, 47:35-8.

Lin YS, Yang ML. 2006. Familial premature ovarian failure in female premutated carriers of fragile $\mathrm{X}$ syndrome: case report and literature review. Taiwan J Obstet Gynecol, 45:60-3.

Lucignani G, Panzacchi A, Bosio L, et al. 2004. GABA ${ }_{A}$ receptor abnormalities in Prader-Willi syndrome assessed with positron emission tomography and $\left[{ }^{11} \mathrm{C}\right]$ flumazenil. Neuroimage, 22:22-8.

Lyketsos CG, Kozauer N, Rabins PV. 2007. Psychiatric manifestations of neurologic disease: where are we headed? Dialogues Clin Neurosci, 9:111-24.

Majerus S, Van der Linden M, Braissand V, et al. 2007. Verbal short-term memory in individuals with chromosome 22q11.2 deletion: specific deficit in serial order retention capacities. Am J Ment Retard, 112:79-93.

Millar J, Mackie S, Clapcote J, et al. 2007. Disrupted in schizophrenia 1 and phosphodiesterase 4B: towards an understanding of psychiatric illness. J Physiol, 584(Pt 2):401-5.

Miller JL, Couch JA, Schmalfuss I, et al. 2006. Intracranial abnormalities detected by three-dimensional magnetic resonance imaging in PraderWilli syndrome. Am J Med Genet, 143A:476-83.

Moore CJ, Daly EM, Tassone F, et al. 2004. The effect of pre-mutation of $\mathrm{X}$-chromosome CGG trinucleotide repeats on brain anatomy. Brain, $127: 2672-81$

Muir WJ, Pickard BS, Blackwood DHR. 2006. Chromosomal abnormalities and psychosis. Br J Psychiatry, 188:501-3.

Murphy KC, Jones LA, Owen MJ. 1999. High rates of schizophrenia in adults with velo-cardio-facial syndrome. Arch Gen Psychiatry, 56:940-45.

Papoulos DF, Faedda GL, Veit S, et al. 1996. Bipolar spectrum disorders in patients diagnosed with velo-cardio-facial syndrome: does a hemizygous deletion of chromosome 22q11 results in bipolar affective disorder? Am J Psychiatry, 153:1541-47.

Paris J. 1994. The etiology of borderline personality disorder: a biopsychosocial approach. Psychiatry, 57:316-25.

Penagarikano O, Mulle JG, Warren ST. 2007. The pathophysiology of fragile X syndrome. Annu Rev Genomics Hum Genet, 8:109-29.

Robin NH, Raylor CJ, McDonald-McGinn DM, et al. 2006. Polymicrogyria and deletion 22q11.2 syndrome: window to the etiology of a common cortical malformation. Am J Med Genet, 140A:2416-25.

Roberts AE, Araki T, Swanson KD, et al. 2006. Germline gain-of-function mutations in SOS1 cause Noonan syndrome. Nat Genet, 39:70-4.

Robin NH, Raylor CJ, McDonald-McGinn DM, et al. 2006. Polymicrogyria and deletion 22q11.2 syndrome: window to the etiology of a common cortical malformation. Am J Med Genet, 140A:416-25.

Salvador-Carulla L, Bertelli M. 2007. 'Mental Retardation' or 'Intellectual Disability': time for a conceptual change. Psychopathology, 41:10-16.

Sarimski K. 2000. Developmental and behavioural phenotype in Noonan syndrome? Genet Couns, 4:383-90.

Schaer M, Schmitt JE, Glaser B, et al. 2006. Abnormal patterns of cortical gyrification in velo-cardio-facial syndrome (deletion 22q11.2): an MRI study. Psychiatry Res, 146:1-11.

Shaw SH, Kelly M, Smith AB, et al. 1998. A genome-wide scan for schizophrenia susceptibility genes. Am J Med Genet, 81:364-76.

Sheldon L, Turk J. 2000. Monozygotic boys with fragile X syndrome. Dev Med Child Neurol, 42:768-74.

Shprintzen RJ, Goldberg R, Golding-Kushner KJ, et al. 1992. Late-onset psychosis in the velo-cardio-facial syndrome. Am J Med Genet, 42:141-42.
Shprintzen RJ. 2000. Velo-cardio-facal syndrome: a distinctive behavioral phenotype. Ment Retard Dev Disabil Res Rev, 6:142-47.

Schubbert S, Zenker M, Rowe SL, et al. 2006. Germline KRAS mutations cause Noonan syndrome. Nat Genet, 38:331-36.

Soni S, Whittington J, Holland AJ, et al. 2007. The course and outcome of psychiatric illness in people with Prader-Willi syndrome: implications for management and treatment. J Intellect Disabil Res, 51:32-42.

StClair D, Blackwood D, Muir W, et al. 1990. Association within a family of a balanced autosomal translocation with major mental illness. Lancet, 336:13-16.

Sugama S, Namihira T, Matsuoka R, et al. 1999. Psychiatric inpatients and chromosome deletions within 22q11.2. J Neurol Neurosurg Psychiatry, 67:803-6.

Swaab DF, Purba JS, Hofman MA. 1995. Alterations in the hypothalamic paraventricular nucleus and its oxytocin neurons (putative satiety cells) in Prader-Willi syndrome: a study of five cases. J Clin Endocrinol Metab, 50:573-9.

Swillen A, Vandeputte L, Cracco J, et al. 1999. Neuropsychological, learning and psychosocial profile of primary school aged children with the velo-cardio-facial syndrome (22q11 deletion): evidence for a nonverbal learning disability. Child Neuropsychol, 5:230-41.

Tartaglia M, Gelb BD. 2005. Noonan syndrome and related disorders: genetics and pathogenesis. Annu Rev Genomics Hum Genet, 6:45-68

Tartaglia M, Mehler E, Goldberg R, et al. 2001. Mutations in the PTPN11, encoding for the protein tyrosine phosphatase SHP-2, cause Noonan syndrome. Nat Genet, 29:465-8.

Tartaglia M, Pennacchio LA, Zhao C, et al. 2007. Gain-of-function SOS1 mutations cause a distinctive form of Noonan syndrome. Nat Genet, 39:75-9.

Tassone F, Beilina A, Carosi C, et al. 2007. Elevated FMR1 mRNA in premutation carriers is due to increased transcription. $R N A$, 13:555-62.

Tuerlings J, De France H, Hamers A, et al. 1998. Chromosome studies in 1792 males prior to intra-cytoplasmic sperm injection: the Dutch experience. Eur J Hum Genet, 6:194-200.

Turk J, Hill P. 1995. Behavioural phenotypes in dysmorphic syndromes. Clin Dysmorphol, 4:105-15.

Van Amelsfoort Th, Daly E, Henry J, et al. 2004. Brain anatomy in adults with velocardiofacial syndrome with and without schizophrenia. Arch Gen Psychiatry, 61:1085-96.

Van Amelsfoort, Th, Zinkstok J, Gigee M, et al. 2008. Effects of functional COMT polymorphism on brain anatomy and cognitive function in adults with velo-cardio-facial syndrome. Psychol Med, 38:89-100.

Van der Burgt I, Thoonen G, Roosenboom N, et al. 1999. Patterns of cognitive functioning in school aged children with Noonan Syndrome associated with variability in phenotypic expression. $J$ Pediatr, 135:707-13

Van der Burgt I, Berends E, Lommen E. 1994. Clinical and molecular studies in a large Dutch family with Noonan syndrome. Am J Med Genet, 53:187-91.

Van Praag HM. 2000. Nosologomania: a disorder of psychiatry. World $J$ Biol Psychiatry, 1:151-8

Verhoeven WMA, Tuinier S. 2001. Two steps forward, one step back: paradigmatic changes in psychiatry. $J$ Neural Transm, 108:617-27.

Verhoeven WMA, Tuinier S. 2006. Prader-Willi syndrome: atypical psychoses and motor dysfunctions. Int Rev Neurobiol, 72:119-30.

Verhoeven WMA, Curfs LMG, Tuinier S. 1998. Prader-Willi syndrome and cycloid psychoses. J Intellect Disabil Res, 42:55-62.

Verhoeven W, Sijben A, Tuinier S. 2004. Psychiatric consultation in intellectual disability; dimensions, domains and vulnerability. Eur $J$ Psychiat, 18:31-43.

Verhoeven WMA, Tuinier S, Curfs LMG. 2003a. Prader-Willi syndrome: cycloid psychosis in a genetic subtype? Acta Neuropsychiatr, 15:32-7.

Verhoeven WMA, Tuinier S, Curfs LMG. 2003b. Prader-Willi syndrome: the psychopathological phenotype in uniparental disomy. J Med Genet, 40:e112. 
Verhoeven WMA, Gunning WB, Tuerlings JHAM, et al. 2006. Psychosen en epilepsie. Tijdschr Psychiatr, 48:809-14.

Verhoeven W, Egger J, Tuinier S. 2007. Thoughts on the behavioural phenotypes in Prader-Willi syndrome and velo-cardio-facial syndrome: a novel approach. Acta Neuropsychiatr, 19:244-50.

Verhoeven WMA, Wingbermühle E, Egger J, et al. 2008. Noonan syndrome: psychological and psychiatric aspects. Am J Med Genet, 146A:191-96.

Verhoeven W, Van Ravenswaaij-Arts C, De Leeuw N, et al. 2006. Distrubed serine mtabolism and psychosis in a patiënt with a de novo translocation $(2 ; 10)(\mathrm{p} 23 ; \mathrm{q} 22.1)$. Genet Couns, 17:421-8.

Verhoeven W, Tuerlings J, Van Ravenswaaij-Arts C, et al. 2007. Chromosomal abnormalities in clinical psychiatry: a report of two older patiënts. Eur J Psychiatr, 21:207-11.

Vitelli F, Morishima M, Taddei I, et al. 2002. Tbx1 mutation causes multiple cardiovascular defects and disrupts neural crest and cranial nerve migratory pathways. Hum Mol Genet, 11:915-22.

Vogels A, Verhoeven WMA, Tuinier S, et al. 2002. The psychopathological phenotype of velo-cardio-facial syndrome. Ann Genet, 45:89-95.
Vogels A, Matthijs G, Legius E, et al. 2003. Chromosome 15 maternal uniparental disomy and psychosis in Prader-Willi syndrome. $J$ Med Genet, 40:72-3.

Vorstman JAS, Morcus MEJ, Duijff SN, et al. 2006. The 22q11.2 deletion in children: high rate of autistic disorders and early onset of psychotic symptoms. J Am Acad Child Adolesc Psychiatry, 45:1104-13.

Welt CK, Smith PC, Taylor AE. 2004. Evidence of early ovarian aging in fragile X premutation carriers. $J$ Clin Endocrinol Metab, 89:4569-74.

Wigren M, Hansen S. 2005. ADHD symptoms and insistence on sameness in Prader-Willi syndrome. J Intellect Disabil Res, 49:449-56.

Williams HJ, Owen MJ, O'Donovan MC. 2007. Is COMT a susceptibility gene for schizophrenia? Schizophr Bull, 33:635-41.

Wood A, Massarano A, Super M, et al. 1995. Behavioural aspects and psychiatric findings in Noonan's syndrome. Arch Dis Child, 72:153-5.

Zanella S, Barthelemy M, Muscatelli F, et al. 2008. Necdin gene, respiratory disturbances and Prader-Willi syndrome. Adv Exp Med Biol, 605:159-64. 
